\title{
Analysis of Islet Cell Antibodies on Frozen Sections of Human Pancreas
}

\author{
B. Marner ${ }^{1}$, Å. Lernmark ${ }^{1}$, J. Nerup 2 , J. L. Molenaar ${ }^{3}$, C. W. Tuk ${ }^{3}$, and G. J. Bruining ${ }^{4}$ \\ 'Hagedorn Research Laboratory, ${ }^{2}$ Steno Memorial Hospital, Gentofte, Denmark, ${ }^{3}$ Stichting Samenwerking Delftse Ziekenhuizen, Delfts, and \\ ${ }^{4}$ Sophia Children's Hospital, Rotterdam, The Netherlands
}

\begin{abstract}
Summary. The sensitivity and specificity of the assay for islet cell cytoplasmic antibodies in human serum were examined using cryostat sections from fresh frozen pancreas. The specificity of the assay was close to $100 \%$ while the sensitivity was $40 \%-98 \%$ depending on the pancreas used. Inter-observer variation was $12-27 \%$. End-point titres of islet cell antibodies varied with the sensitivity of each pancreas. End-point titration of the antibodies in two different laboratories using the same pancreas was significantly correlated (Spearman test
\end{abstract}

$p<0.001$ ). We conclude that a reliable determination of islet cell antibody titres in human serum requires careful characterization of the sensitivity and specificity of each pancreas used as a source of frozen sections, in the indirect immunofluorescence assay.

Key words: Islet cell antibodies, indirect immunofluorescence, insulin-dependent diabetes, assay reproducibility, assay precision.
Antibodies reactive with determinants in the cytoplasm of pancreatic islet cells are found in many patients with newly diagnosed Type 1 (insulin-dependent) diabetes. These islet cell cytoplasmic antibodies (ICA) are detected with indirect immunofluorescence assays on sections of human blood group 0 pancreas [1-4]. Several investigators have studied the prevalence of islet cell antibodies in diabetes [5-9] among family members [10-13] in correlation with other autoimmune diseases $[1,8,9$, $11,14,15]$ and their occurrence in the background population [15]. Furthermore, ICA have been claimed to be a marker of an ongoing pathological process in antibody-positive individuals eventually developing Type 1 diabetes [12].

The usefulness of the ICA assay as a diagnostic test remains limited since assay reproducibility and precision have not been defined. Early attempts to detect ICA were hampered by a marked non-specific fluorescent reaction due to the blood group of the pancreas donor [2]. A description of requirements for the ICA fluorescence assay, including choice and storage of the pancreas, has been published previously [17], but standardized evaluation of the fluorescent reactions, as well as assay reproducibility, precision, and sensitivity remain to be defined.

The aim of the present study was to examine (1) titres and variability of ICA determined on sections of different human pancreatic specimens, (2) the assay re- producibility in terms of both day-to-day and reader-toreader variation, and (3) the assay variability between two laboratories using the same substrate.

\section{Subjects and Methods}

\section{Patients}

Plasma was obtained within 15 days of diagnosis of Type 1 diabetes from 10 patients (aged 11-16 years, mean 13 years; six boys and four girls). Sera from 10 age- and sex-matched healthy children and nine healthy adults were used as controls. No control had a first-degree relative with diabetes. Diabetic and control samples were kindly provided by J. Ludvigsson, Linköping, Sweden. In addition, a pool of sera from patients with high titres of insulin antibodies was tested. All plasma samples were kept frozen during shipment and storage. Control experiments with serum and plasma obtained from the same individual and with immunoglobulin purified by polyethyleneglycol $(12.5 \%, \mathrm{w} / \mathrm{v})$ precipitation and subsequent standard DEAE-Sephadex chromatography showed no difference in ICA titres for 10 Type 1 patients.

\section{Pancreatic Specimens}

Blood group 0 pancreatic tissue was obtained from two patients undergoing abdominal surgery not directly involving the pancreas and from seven post-mortem kidney donors (Table 1). The kidney donors were victims of accidents and did not have any systemic or major vascular disease. Severe hypotension or multiple crises had not occurred in any before removal of the kidneys and pancreas. Ischaemia time 
Table 1. Sensitivity and specificity of ICA determinations on seven different pancreas

\begin{tabular}{|c|c|c|c|c|c|c|c|c|}
\hline \multirow[t]{2}{*}{ Pancreas } & \multirow{2}{*}{$\begin{array}{l}\text { Age } \\
\text { (years) }\end{array}$} & \multirow[t]{2}{*}{ Sex } & \multirow{2}{*}{$\begin{array}{l}\text { Organ } \\
\text { retrieval }\end{array}$} & \multirow{2}{*}{$\begin{array}{l}\text { Ischaemia } \\
\text { time (min) }\end{array}$} & \multicolumn{2}{|c|}{ Sensitivity ${ }^{\mathrm{a}}$} & \multicolumn{2}{|c|}{ Specificity ${ }^{b}$} \\
\hline & & & & & $+/$ total & $\%$ & $-/$ total & $\%$ \\
\hline $\mathrm{H} 84$ & 21 & $\mathrm{~F}$ & Surgery & $<15$ & $239 / 245$ & $98(96-99)$ & $189 / 192$ & $98(96-100)$ \\
\hline $\mathrm{H} 67$ & 17 & M & Necropsy & $<15$ & $105 / 110$ & $96(90-99)$ & $66 / 69$ & $96(88-99)$ \\
\hline $\mathrm{HP}$ & 35 & $\mathrm{~F}$ & Surgery & $<15$ & $240 / 255$ & $94(90-97)$ & $172 / 178$ & $97(93-99)$ \\
\hline $\mathrm{H} 75$ & 7 & $\mathrm{M}$ & Necropsy & 110 & $129 / 140$ & $92(86-96)$ & $69 / 69$ & $100(95-100)$ \\
\hline $\mathrm{H} 80$ & 29 & M & Necropsy & $<15$ & $138 / 184$ & $75(68-81)$ & $77 / 77$ & $100(95-100)$ \\
\hline $\mathrm{H} 63$ & 63 & $\mathrm{~F}$ & Necropsy & 70 & $32 / 43$ & $74(59-87)$ & $32 / 32$ & $100(89-100)$ \\
\hline $\mathrm{H} 57$ & 33 & $\mathbf{M}$ & Necropsy & 120 & $12 / 30$ & $40(23-59)$ & $16 / 16$ & $100(79-100)$ \\
\hline
\end{tabular}

${ }^{a}$ Sensitivity of ICA assay is expressed as the number of times a diabetic positive control plasma sample (diluted 1:1,1:3,1:9,1:27) was read as positive divided by the number of times this sample was tested $(+/$ total $) ; b$ specificity of ICA assay is expressed as the number of times a negative control plasma sample was read as negative divided by the number of times the sample was tested ( $-/$ total). $95 \%$ confidence limits of the $\%$ sensitivity and specificity are shown in parentheses

Table 2. Islet cell cytoplasmic antibody titres in 11 plasma samples tested on seven different pancreas

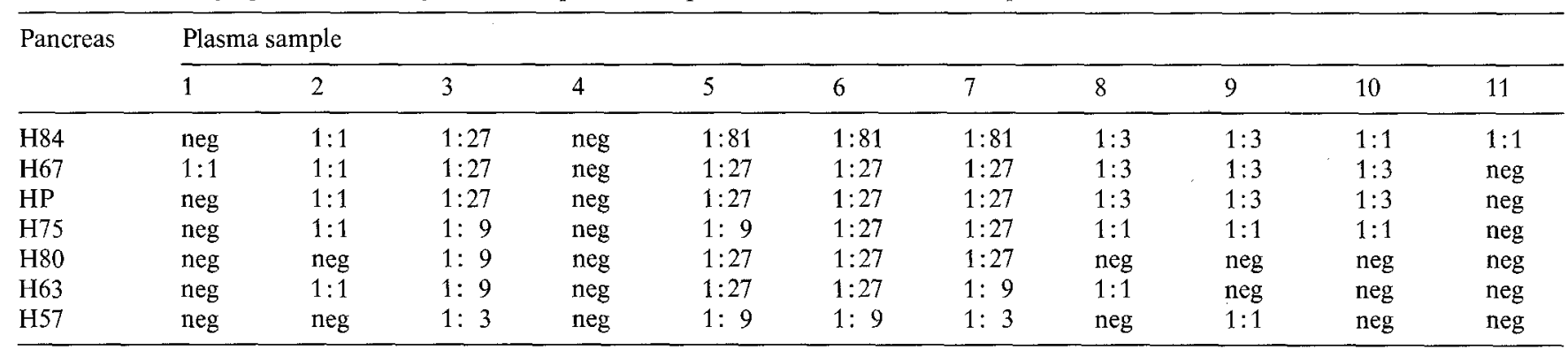

Plasma samples 1-10 were obtained from newly diagnosed Type 1 diabetic patients without insulin antibodies. Sample 11 is a pool of plasma samples from insulin-treated patients with high titres of insulin antibodies

(i.e. the time from cessation of circulation in the donor until freezing the tissue) was kept as short as possible $(15-120 \mathrm{~min})$. The pancreases were cut into pieces $0.5 \mathrm{~cm}^{3}$, frozen in isopentane $\left(-160^{\circ} \mathrm{C}\right)$ and stored at $-80^{\circ} \mathrm{C}$ in airtight bags. In addition, pieces of one pancreas (HP) were fixed in Bouin's solution and embedded in paraffin.

\section{Indirect Immunofluorescence Assay}

Paraffin and cryostat sections were cut 3-4 $\mu \mathrm{m}$ thick. Cryostat sections were air dried at room temperature for $30 \mathrm{~min}$ under a fan. Plasma or serum samples $(30-50 \mu 1)$ were pipetted directly onto the section and incubated for $30 \mathrm{~min}$ at room temperature in a moist chamber. The slides were washed for $3 \times 5 \mathrm{~min}$ in phosphate buffered saline ( $\mathrm{pH}$ 7.2) before application of fluorescein isothiocyanate conjugated rabbit anti-human IgG (1:10 dilution, 30-50 $\mu$ l, Dakopatts, Copenhagen, Denmark). The slides were incubated in the dark for $30 \mathrm{~min}$ at room temperature and then washed in phosphate buffered saline as above. The sections were finally mounted in $20 \%$ glycerol buffered with $50 \mathrm{mmol} / 1$ Tris $\mathrm{HCl}(\mathrm{pH} 8.4)$.

All plasma samples were tested at least twice both undiluted (1:1) and diluted in phosphate buffered saline $1: 3(33.3 \%, \mathrm{v} / \mathrm{v}$ plasma $), 1: 9$ $(11.1 \%), 1: 27(3.6 \%)$, and 1:81 (1.2\%). The sections were evaluated using a Zeiss Universal microscope with epi-illumination.

\section{Evaluation of Fluorescence}

Each preparation was evaluated by two or three investigators who were not informed of the identity of the sample, the dilution, or the pancreas. Positive and negative control samples, at four different dilutions, were included randomly in each assay. A sample was considered positive if at least three to seven islets in a section showed fluorescence when viewed at a magnification of X300. If the islet fluorescence could not be distinguished from fluorescence in the ex- ocrine tissue, the preparation was considered negative. All samples were tested twice. A third assay was carried out if investigators scored a sample differently within an assay or between the two different assays.

\section{Inter-laboratory Variation}

Two different laboratories (Gentofte and Delft) used frozen sections of pancreas (HP) (Table 1) to investigate 46 plasma samples (37 samples from children with Type 1 diabetes and nine adult control subjects). Both laboratories measured the end-point titration of positive results following their own laboratory routines for sectioning, preparation of samples, buffers and fluorescent reagents as well as for microscopy. The indirect immunofluorescence test was carried out as described above in the Gentofte laboratory, but the following modifications occurred in the Delft Laboratory: the samples were tested undiluted (1:1), and diluted $1: 2(50 \% \mathrm{v} / \mathrm{v}$ plasma), $1: 4(25 \%), 1: 8$ $(12.5 \%)$, and $1: 16(6.25 \%)$ in heat-inactivated normal rabbit serum; rabbit anti-human IgG FITC (Central Laboratory of the Blood Transfusion Service, Amsterdam) was diluted 1:50 in phosphate buffered saline; and the specimens were evaluated in a Leitz orthoplan microscope with epi-illumination.

\section{Results}

\section{Specificity and Sensitivity of ICA Determinations on Different Pancreas}

The results of repeated readings of plasma samples from an ICA-positive diabetic subject and an ICA-negative normal individual on sections from seven different 
Table 3. Inter-observer variation in evaluating islet cell cytoplasmic antibodies

\begin{tabular}{|c|c|c|c|c|c|}
\hline \multirow{3}{*}{$\begin{array}{l}\text { Observers } \\
\mathrm{BM} \text { and } \AA ̊ \mathrm{~L}\end{array}$} & \multirow{3}{*}{$\begin{array}{l}\begin{array}{l}\text { Plasma } \\
\text { dilution }\end{array} \\
1: 1\end{array}$} & \multicolumn{4}{|c|}{ Fluorescence readings } \\
\hline & & \multirow{2}{*}{$\frac{\text { Concordant }}{636}$} & \multicolumn{2}{|c|}{ Discordan $^{\mathrm{a}}$} & \multirow{5}{*}{$\begin{array}{r}(10-15) \\
(9-15) \\
(8-15) \\
(6-13)\end{array}$} \\
\hline & & & 90 & $12 \%$ & \\
\hline & $1: 3$ & 428 & 61 & $13 \%$ & \\
\hline & 1: 9 & 314 & 37 & $11 \%$ & \\
\hline & $1: 27$ & 212 & 20 & $9 \%$ & \\
\hline & $\begin{array}{l}\text { Total } \\
\text { readings }\end{array}$ & 1590 & 208 & $12 \%$ & $(10-13)$ \\
\hline \multirow[t]{5}{*}{$\mathrm{BM}$ and $\mathrm{JN}$} & 1: 1 & 376 & 64 & $15 \%$ & $(12-18)$ \\
\hline & $1: 3$ & 265 & 44 & $14 \%$ & $(11-19)$ \\
\hline & 1: 9 & 204 & 33 & $14 \%$ & $(10-20)$ \\
\hline & $1: 27$ & 111 & 40 & $27 \%$ & $(18-37)$ \\
\hline & $\begin{array}{l}\text { Total } \\
\text { readings }\end{array}$ & 956 & 181 & $16 \%$ & $(14-18)$ \\
\hline \multicolumn{2}{|c|}{$\mathrm{BM}, \AA \AA \mathrm{L}$, and $\mathbf{J N}$} & 2935 & 389 & $12 \%$ & $(12-15)$ \\
\hline
\end{tabular}

205 different plasma samples from 28 subjects and a positive and negative control plasma were assayed 2-40 times on six different pancreas by three independent observers.

a $\%$ discordant fluorescence readings with $95 \%$ confidence limits interpolated from standard tables of binominal distribution shown in parentheses

frozen pancreas are shown in Table 1 . The sensitivity of these pancreas for detection of the ICA-positive plasma ranged from $40 \%$ to $98 \%$. The variability in sensitivity seemed to be influenced both by the age of the donor and the period of ischaemia. Thus, one pancreas $(\mathrm{H} 75)$ from a young donor, 7 years old, showed $92 \%$ sensitivity despite 110 min of ischaemia, (H63) was less sensitive (74\%) and a pancreas from a 33-year old donor with 120 min of ischaemia (H57) gave only $40 \%$ sensitivity in the ICA assay. Although the sensitivity of the different pancreas in detecting the ICA-positive control plasma was quite variable, the probability that a negative control plasma sample added randomly among samples in every assay would be read as negative (specificity of ICA assay) was high for all seven pancreas (Table 1).

The differing sensitivities of the various pancreas in detecting an ICA-positive plasma were reflected in the measurement of ICA titres in $\mathbf{1 1}$ different diabetic plasma samples (Table 2). Thus, the listing of pancreatic specimens in order of decreasing sensitivity (as determined in Table 1) is generally associated with a progressive decrease in ICA titre in each individual plasma sample tested. In contrast, sample 11, which had a high level of insulin antibodies (titre 1:9 on Bouin-fixed pancreas (HP)) was mostly negative for ICA on frozen pancreas.

\section{Inter-observer Variation}

Positive and negative controls were mixed randomly with test samples and the fluorescence read as positive

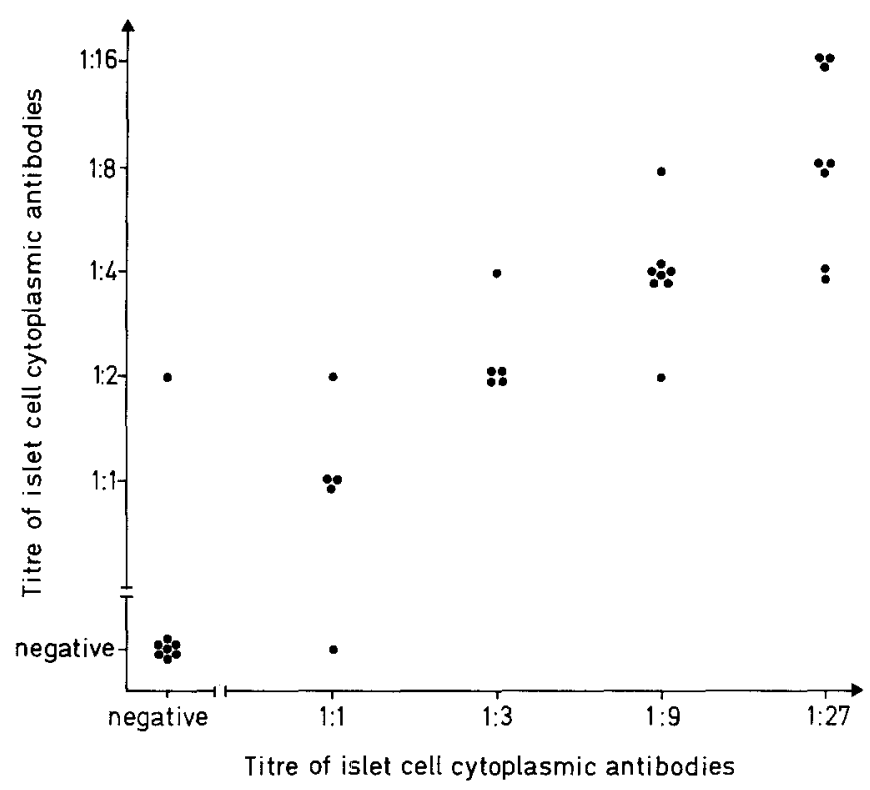

Fig. 1. Variation in the determination of islet cell cytoplasmic antibodies between two different laboratories. Pancreas HP (Tables 1 and 2 for details) was used to determine the end-point titre in 37 plasma samples from 10 Type 1 diabetic patients and nine samples from normal subjects. Correlation by the Spearman's rho test, $\mathrm{r}_{\mathrm{s}}=0.908$; $(p<0.001)$. All the normal samples were found negative in both laboratories and are not shown in the figure

or negative by three different observers without knowing the identity of the samples (Table 3). The inter-observer variation (discordance) was 9\%-15\% except at a $1: 27$ plasma dilution where two of the observers (BM and $\mathrm{JN}$ ) were discordant by $27 \%$.

\section{Inter-laboratory Variation}

The ICA titres determined independently by the two laboratories correlated well although scored consistently somewhat lower by one of them (Figure 1).

\section{Discussion}

Our study demonstrates that the specificity of the ICA assay was little influenced by the pancreas used, i.e. false positive readings were negligible. However, the sensitivity of ICA determinations was markedly dependent on the pancreas used as the source for the frozen tissue sections. Since some pancreatic specimens underestimated the presence of ICA (false negative), it is advisable to check the sensitivity of all pancreas to be used for ICA determinations. This criteria is particularly important in long-term prospective analyses of individuals susceptible to diabetes.

Recent observations suggest that circulating ICA may precede the onset of diabetes by several years $[12$, 14]. Some factors of importance in selecting a suitable pancreas were suggested in the present study. Apart from the blood group (type 0) [1], the age of the patient 
and the period of ischaemia appeared to be important, more sensitive pancreas being obtained from younger donors and/or after only a short period of ischaemia $(<15 \mathrm{~min})$. Another important variable may be the preservation of the pancreas. We have stored our frozen pancreatic specimens in airtight bags at $-80^{\circ} \mathrm{C}$ routinely for more than 1 year without decrease in sensitivity. Sera from ten newly diagnosed Type 1 diabetic patients showed different degrees of reactivity with frozen sections from 7 different pancreas (Table 2). The more sensitive pancreas clearly distinguished between low and high titre ICA-containing plasmas. In accordance with recent observations [18-20] the plasmas from the 10 Type 1 diabetic patients showed little if any reactivity with islets in Bouin-fixed sections of the pancreas (HP). Although this pancreas was quite sensitive in detecting ICA when prepared in frozen sections.

The end-point titre represents a useful measure of circulating islet cell antibodies. Pancreas of high sensitivity detected ICA in titres of $1: 27-1: 81$ in several of the diabetic patients studied. Titration of ICA may be a useful approach in defining more accurately the role of circulating ICA in diabetes and in testing for correlation of the antibodies with clinical characteristics. Lendrum et al. [5] found ICA titres to range from 1:1 to $1: 256$ with the geometric mean titre slightly higher at onset than after diabetes of long duration. In many studies, titres are not reported and there is little or no information about reproducibility and precision [21]. Our data demonstrate that the mean inter-observer variation was $13 \%$. Also, there was good inter-laboratory agreement in ICA titres when the same pancreas and plasma samples were used, but all other variables, such as fluorescent antibodies, evaluation, and instrumentation were varied. The lower titres scored by one of the laboratories could be explained by the difference in fluorescent antibodies and the fact that dilutions were made in rabbit serum.

These results indicate that the immunofluorescence assay for ICA is applicable quantitatively for testing the possible importance of circulating antibodies relative to the development or progression of diabetes, provided all pancreatic substrates are characterized in terms of sensitivity and specificity, and the antibody titre is determined by end-point titration, preferably by two independent observers.

Acknowledgements. We thank K. Solberg and H.Jensen at the department of Clinical Chemistry, Kommunehospitalet in Copenhagen and T. Thoreinsdottir for skillful technical assistance. The Pathology Department at Herlev Hospital, University of Copenhagen is acknowledged for allowing us to use the cryostat. The surgeons at the State University Hospital (Rigshospitalet), The Glostrup, Herlev, and Hvidovre Hospitals at the University of Copenhagen, and the Academic Digtezigt Hospital, Rotterdam are thanked for supplying pancreatic material. We are grateful to A. Rabinovitch for carefully revising the manuscript. The study was supported in part by the National Institutes of Health (AM-26190) and Landsforeningen for Sukkersyge.

\section{References}

1. Bottazzo GF, Florin-Christensen A, Doniach D (1974) Islet-cell antibodies in diabetes mellitus with autoimmune polyendocrine deficiencies. Lancet 2: 1279-1282

2. Lendrum R, Walker G (1975) Serum antibodies in human pancreatic disease. Gut 16:365-371

3. Dobersen MH, Bell AM, Jenson AB, Notkins AL (1979) Detection of antibodies to islet cells and insulin with paraffin-embedded pancreas as antigen. Lancet 2: 1078

4. Sewell H, Smith DI, Willox A, Barnes CA (1980) Demonstration of islet-cell antibodies. Lancet 1: 102-103

5. Lendrum R, Walker G, Theophanides C, Pyke DA, Bloom A, Gamble DR (1976) Islet-cell antibodies in diabetes mellitus. Lancet $2: 1273-1276$

6. Freedman ZR, Feek CM, Irvine WJ, Lernmark $\AA$, Rubenstein AH, Steiner DF, Huen A (1979) Islet cell cytoplasmic and cell surface antibodies in diabetes mellitus. Trans Assoc Phys XCII: 65-75

7. Lernmark $\AA$, Hägglöf $B$, Freedman ZR, Irvine $\mathbf{J}$, Ludvigsson $\mathbf{J}$, Holmgren $G$ (1981) A prospective analysis of antibodies reacting with pancreatic islet cells in insulin-dependent diabetes children. Diabetologia $20: 471-474$

8. Irvine WJ, McCallum CJ, Gray RS, Campbell CJ, Duncan LJP, Farquhar JW, Vaughan H, Morris PJ (1977) Pancreatic islet-cell antibodies in diabetes mellitus correlated with the duration and type of diabetes, coexistent autoimmune disease, and HLA type. Diabetes 26: 138-147

9. Madsbad S, Bottazzo GP, Cudworth AG, Dean B, Faber OK, Binder C (1980) Islet cell antibodies and beta cell function in insulindependent diabetics. Diabetologia 18: 45-47

10. Bottazzo GF, Mann JI, Thorogood M, Baum JD, Doniach D (1978) Autoimmunity in juvenile diabetics and their families. $\mathrm{Br}$ Med J 2: 165-168

11. Gorsuch AN, Dean BM, Bottazzo GF, Lister J, Cudworth AG (1980) Evidence that Type 1 diabetes and thyrogastric autoimmunity have different genetic determinants. Br Med J 1: 145-147

12. Gorsuch AN, Spencer KM, Lister J, McNally JM, Dean BM, Bottazzo GF (1981) Evidence for a long prediabetic period in Type 1 (insulin-dependent) diabetes mellitus. Lancet 2: 1363-1364

13. Betterle C, Zanette F, Tiengo A, Trevisan A (1982) Five-year follow-up on non-diabetes with islet-cell antibodies. Lancet 1: 284-285

14. Irvine WJ, Gray RS, McCallum CJ (1976) Pancreatic islet-cell antibodies as a marker for asymptomatic and latent diabetes and prediabetes. Lancet 2: 1098-1102

15. MacCuish AC, Barnes EW, Irvine WJ, Duncan LJP (1974) Antibodies to pancreatic islet cells in insulin-dependent diabetics with coexistent autoimmune disease. Lancet 2: 1529-1531

16. Rodger B, Wittingham S, Martin FIR, Hawkins BR, Hawkins RL, Welborn TA (1980) A population survey of pancreatic islet cell antibodies. Clin Exp Immunol 89: 125-129

17. Doniach D, Bottazzo GF (1977) Autoimmunity and the endocrine pancreas. Pathobiology Annual 7: 327-346

18. Yagihashi S, Suzuki H, Dobersen MJ, Onodera T, Notkins AL (1982) Autoantibodies to islet cells: comparison of methods. Lancet 2: 1218

19. Dean BM, Pujol-Borrell R, Bottazzo GF (1982) Determination of islet-cell antibodies by immunofluorescence. Lancet $2: 1343-1345$

20. Rosenbloom AL (1983) Autoantibodies to islet cells; comparison of methods. Lancet $1: 72-73$

21. Nerup J, Lernmark Â (1981) Autoimmunity in diabetes mellitus. Am J Med 70: 135-141

Received: 30 November 1982

and in revised form: 1 June 1983

Dr. Birgitte Marner

Hagedorn Research Laboratory

Niels Steensensvej 6

DK-2820 Gentofte

Denmark 